\title{
RISIKO GAYA HIDUP TERHADAP KEJADIAN KANKER PAYUDARA PADA WANITA
}

\section{Lifestyle Risk Factors of Women with Breast Cancer}

\author{
Ida Leida Maria ${ }^{1}$, Andi Asliana Sainal ${ }^{1}$, Mappeaty Nyorong ${ }^{2}$ \\ ${ }^{1}$ Departemen Epidemiologi, FKM Universitas Hasanuddin, \\ ${ }^{2}$ Departemen Studi Promosi Kesehatan, FKM Universitas Hasanuddin, \\ (idale_262@yahoo.com)
}

\begin{abstract}
ABSTRAK
Kanker payudara merupakan keganasan umum pertama pada wanita di seluruh dunia dan menjadi pembunuh nomor dua dari keseluruhan kanker di Indonesia. Penelitian ini bertujuan mengetahui faktor risiko gaya hidup yaitu konsumsi lemak, obesitas, merokok dan stres pada wanita yang menderita kanker payudara di rumah sakit Kota Makassar tahun 2016. Jenis penelitian observasional analitik dengan rancangan case control study, pengumpulan data menggunakan kuesioner, uji statistik bivariat menggunakan odds ratio dengan $\alpha=0,05$ dan multivariat menggunakan analisis regresi berganda logistik. Hasil penelitian menunjukkan bahwa berdasarkan hasil uji statistik dengan menggunakan OR, diketahui bahwa faktor risiko yang signifikan terhadap kejadian kanker payudara adalah konsumsi lemak $\geq$ nilai rata-rata seluruh penderita/responden $(\geq 97)(p=0,005$, $\mathrm{OR}=2,872$;CI 95\%:1,410-5,849), obesitas (IMT $\left.\geq 25 \mathrm{~kg} / \mathrm{m}^{2}\right) \quad(\mathrm{p}=0,069, \mathrm{OR}=1,942, \mathrm{CI} 95 \%: 1,006-3,749)$, merokok $(\mathrm{p}=0,063, \mathrm{OR}=2,002 ; \mathrm{CI} 95 \%: 1,020-3,930)$, dan stres $(\mathrm{p}=0,012, \mathrm{OR}=2,698 ; \mathrm{CI} 95 \%: 1,294-5,624)$. Stres merupakan variabel yang paling berpengaruh terhadap kejadian kanker payudara $(\mathrm{p}=0,020, \mathrm{OR}=2,657 ; \mathrm{CI} 95 \%: 1,166-6,054)$. Kesimpulannya adalah faktor risiko yang berpengaruh terhadap kejadian kanker payudara pada wanita di Rumah Sakit Kota Makassar adalah konsumsi lemak, obesitas, merokok dan stres. Faktor risiko yang paling perpengaruh terhadap kejadian kanker payudara adalah stres.
\end{abstract}

Kata kunci : Kanker payudara, faktor risiko, gaya hidup

\section{ABSTRACT}

Breast cancer is the number one most common malignancy in women worldwide and of all cancers is the second killer in Indonesia. The aim of this research was to analyze the lifestyle risk factors namelyfat intake, obesity, smoking and stress in women with breast cancer in hospitals in Makassar City. The type of research conducted was an analytic observational research with acase-control study design.Data were collected using a questionnaire. The data were analyzed using bivariate statistic test by means of Odds Ratio (OR) with $\alpha=0.05$ and multivariate by means of multiple logistic regression analysis. Based on the statistical test using OR, it was found that the most significant breast cancer risk factors were fat consumption $\geq$ average value of all patients/ respondents $(\geq 97)(p=0.005, O R=2,872 ; C 195 \%: 1,410-5,849)$, obesity $\left(B M I \geq 25 \mathrm{~kg} / \mathrm{m}^{2}\right)(p=0.069, O R=1,942 ; C I$ 95\%:1,006-3,749), smoking $(p=0.063, O R=2,002 ; C I$ 95\%:1,020-3,930), and stress $(p=0.012, O R=2,698 ; C I 95 \%$; $1,294-5,624)$. Stress was the most dominant variable affecting the occurrence of breast cancer $(p=0.020, O R=$ 2.657;CI 95\%:1.166-6.054). In conclusion, the risk factorsaffecting the occurrence of breast cancer in women in the hospital of Makassar City were fat intake, obesity, smoking and stress. The risk factor that was most dominant in affecting the occurrence of breast cancerwas stress.

Keywords : Breast cancer, risk factor, lifestyle 


\section{PENDAHULUAN}

Kanker payudara adalah tumor ganas yang berawal dari dalam sel-sel payudara. Penyakit ini terjadi hampir seluruhnya pada wanita, tetapi pria juga bisa mendapatkannya. ${ }^{1}$ Secara umum diperkirakan kanker payudara merupakan penyebab kematian tertinggi akibat kanker setelah kanker paru. Pada penduduk perempuan, kanker payudara masih menempati urutan pertama kasus baru dan kematian, yaitu sebesar $43,3 \%$ kasus baru dan $12,9 \%$ kematian. $^{2}$

Berdasarkan data Global Burden Cancer, di Amerika Serikat pada tahun 2015 terdapat 231.840 kasus baru kanker payudara dan diestimasi sebanyak 40.290 wanita yang meninggal dunia. Pada tahun 2016 diestimasi jumlah kasus baru meningkat menjadi 246.660 kasus dan sebanyak 40.450 wanita yang meninggal akibat kanker payudara. Kanker payudara di Asia menempati urutan pertama penyakit pada wanita. Estimasi insidensi kanker payudara pada tahun 2012 di Asia adalah sebesar 650.983 kasus $(21,2 \%)$. Estimasi kematian akibat kanker payudara adalah sebesar 231.013 $(12,8 \%) .^{3}$

Prevalensi kanker payudara di Indonesia tertinggi pada provinsi D.I. Yogyakarta yaitu sebesar $0,24 \%$, sedangkan Provinsi Sulawesi Selatan berada pada urutan ke tujuh yaitu sebesar $0,07 \%{ }^{2}$ Terdapat kecenderungan dari tahun ke tahun meningkat. Sebagian besar keganasan payudara datang pada stadium lanjut. ${ }^{4}$ Berdasarkan data rekapan dari Dinas Kesehatan Pemerintah Provinsi Sulawesi Selatan pada tahun 2012 jumlah kasus kanker payudara adalah sebanyak 805 kasus, sedangkan pada tahun 2013 menurun menjadi 749 kasus dan meningkat kembali pada tahun 2014 menjadi 1.051 kasus.

Menurut Perry et al., faktor risiko yang diketahui dapat menyebabkan kanker payudara secara luas dibagi menjadi tiga kategori yaitu hormonal/reproduksi, intrinsik, dan yang diperoleh. Faktor hormonal adalah eksposur hormon steroid. Faktor risiko intrinsik adalah herediter atau yang berkaitan genetik. Faktor risiko yang diperoleh adalah pola hidup atau faktor lingkungan. ${ }^{5}$

Pola hidup merupakan salah satu faktor internal yang memengaruhi kesehatan seseorang. Perilaku untuk meningkatkan kesehatan dapat dikontrol dan dipilih. Pilihan seseorang terhadap sehat tidaknya aktivitas yang dilakukan dipengaruhi oleh faktor sosial kultural karakteristik individu. Perilaku yang bersifat negatif terhadap kesehatan dikenal sebagai faktor risiko. ${ }^{6}$

Potter dan Perry mengemukakan bahwa ada kegiatan dan perilaku yang dapat memberikan efek pada kesehatan. Perilaku yang berpotensi memberikan efek negatif antara lain makan berlebihan atau nutrisi yang buruk, merokok, minum minuman beralkohol, stres akibat krisis kehidupan dan gaya hidup. ${ }^{7}$ Perilaku konsumsi makanan dan minuman junk food atau fast food, dan aneka jenis makanan olahan berpotensi mempercepat pertumbuhan sel kanker. ${ }^{8}$ Organisasi Kesehatan Dunia telah menentukan bahwa faktor pola makan mencakup sedikitnya $30 \%$ dari penyebab seluruh kanker di negara-negara barat dan sampai $20 \%$ di negara-negara berkembang. Semakin gencarnya informasi dan promosi berbagai makanan cepat saji seperti fast food atau junk food yang kaya lemak dan karbohidrat, tetapi rendah serat menyebabkan masyarakat Indonesia mengubah pola makannya. Hal ini diperkuat oleh penelitian yang dilakukan oleh Balasubramaniam et al., yang menemukan bahwa wanita yang mengonsumsi lemak lebih dari $30 \mathrm{~g} /$ hari, memiliki dua kali lipat risiko terkena kanker. ${ }^{9}$

Pola makan yang berlebihan akan mengakibatkan timbulnya obesitas. Indeks Massa Tubuh (IMT) merupakan standar internasional untuk menentukan standar tubuh seseorang. Untuk standar Asia bila IMT $\geq 23 \mathrm{~kg} / \mathrm{m}^{2}$ maka sudah dapat dikatakan sebagai overweight (kelebihan berat badan). Bila IMT $\geq 25 \mathrm{~kg} / \mathrm{m}^{2}$, maka orang tersebut mengalami obesitas. Berdasarkan American Cancer Society, menyatakan bahwa wanita yang mengalami obesitas atau kelebihan berat badan setelah memasuki masa menopause memiliki risiko lebih tinggi menderita kanker payudara. ${ }^{10}$ Menurut Iqbal et al., IMT lebih dari $25 \mathrm{~kg} / \mathrm{m}^{2}$ memiliki risiko terkena kanker payudara sebanyak 5,24 kali. ${ }^{11}$

Selain obesitas salah satu pelilaku negatif terhadap kesehatan adalah merokok. Seorang perokok tujuh kali lebih rentan terhadap jenis kanker termasuk kanker payudara bila dibandingkan dengan non perokok. ${ }^{12}$ Penyelidikan epidemiologis menemukan bahwa kemungkinan merokok pasif untuk kanker payudara jauh lebih besar daripada risiko angka kejadian riwayat merokok aktif. ${ }^{13}$ Asap rokok dapat meningkatkan risiko kanker 
payudara karena mengandung bahan kimia dalam konsentrasi tinggi yang dapat menyebabkan kanker payudara. ${ }^{15}$ Hosseinsadeh et al., menemukan hubungan faktor risiko merokok pasif terhadap kejadian kanker payudara $(\mathrm{OR}=2,76 ; 95 \% \mathrm{CI}$, $1,51-5,04) .^{16}$

Selain perilaku merokok, stres juga merupakan faktor yang dapat menyebabkan kanker payudara. Bila seseorang setelah mengalami stres mengalami gangguan pada satu atau lebih organ tubuh sehingga yang bersangkutan tidak lagi dapat menjalankan fungsinya dengan baik, maka disebut mengalami distres. ${ }^{17}$ Salah satu jenis stres yang dialami adalah stres psikososial (tekanan mental/beban kehidupan) akan mengakibatkan stres psikobiologik yang berdampak pada menurunnya imunitas tubuh. Bila imunitas tubuh menurun maka yang bersangkutan rentan jatuh sakit baik fisik maupun mental yang dapat mengarah pada risiko munculnya sel-sel ganas (kanker). Kashani et al., menemukan hubungan yang signifikan antara stres tehadap kejadian kanker payudara $(\mathrm{p}=0,001) .{ }^{18}$

Penderita kanker payudara di Kota Makassar sebagian besar melakukan kunjungan dan memperoleh pengobatan di rumah sakit. Pemilihan Rumah Sakit Umum Pendidikan Dr. Wahidin Sudirohusodo, RS Ibnu Sina, RS Tk.II Pelamonia, dan RS Islam Faisal sebagai tempat penelitian karena rumah sakit rujukan dari beberapa daerah di Provinsi Sulawesi Selatan yang memiliki layanan kemoterapi dan rumah sakit tersebut mewakili rumah sakit pemerintah dan rumah sakit swasta. Penelitian ini bertujuan menganalisis faktor risiko gaya hidup yaitu konsumsi lemak, obesitas, merokok dan stres terhadap kejadian kanker payudara pada wanita di rumah sakit Kota Makassar tahun 2016.

\section{BAHAN DAN METODE}

Jenis penelitian yang digunakan adalah studi observasional analitik dengan rancangan case control study. Penelitian dilakukan di RSUP Wahidin Sudirohusodo, RS Ibnu Sina, RS Tk.II Pelamonia, dan RS Islam Faisal Kota Makassar tahun 2016. Penelitian ini dilaksanakan pada bulan Oktober-November tahun 2016. Populasi dalam penelitian ini adalah seluruh pasien rawat inap dan rawat jalan penyakit kanker payudara yang terdata di bagian rekam medik di RSUP Dr. Wahidin
Sudirohusodo yaitu sebanyak 352 pasien, RS Ibnu Sina sebanyak 535 pasien, RS Tk. II Pelamonia sebanyak 135 pasien, dan RS Islam Faisal sebanyak 231 pasien. Sampel dalam penelitian ini terbagi dalam dua kelompok yaitu kasus dan kontrol. Kasus merupakan pasien yang menderita kanker payudara berdasarkan diagnosa yang tercatat pada status rekam medik pasien dan kontrol merupakan pasien yang tidak menderita kanker payudara berdasarkan diagnosa yang tercatat pada status rekam medik pasien. Jumlah sampel sebanyak 73 dengan perbandingan antara kasus dan kontrol 1:1. ${ }^{19}$

Penarikan sampel dilakukan dengan metode proporsional stratified random sampling, yaitu sampel random diperoleh dengan membagi berdasarkan rumah sakit. Teknik pengambilan sampel dari masing-masing strata dilakukan dengan cara non-random (non-probability sampling) yaitu melalui teknik purposive sampling dengan berdasarkan kriteria inklusi dan eksklusi. Pengumpulan data dilakukan dengan wawancara terhadap responden dengan berpedoman pada kuesioner yang telah tersedia. Pengolahan data menggunakan komputer dengan aplikasi SPSS (Statistical Package and Social Sciences) versi 20. Analisis data bivariat dilakukan dengan menggunakan perhitungan Odds Ratio dengan $\alpha=0,05$ dan multivariat menggunakan analisis regresi berganda logistik.

\section{HASIL}

Tabel 1 menunjukkan karakteristik responden yang menjadi sampel pada penelitian ini. Distribusi kejadian kanker payudara berdasarkan kelompok umur terbanyak ditemukan pada rentang umur 46-52 tahun. Baik pada kelompok kasus maupun pada kelompok kontrol distribusi responden paling banyak yaitu pada rentang umur 46-52 tahun yaitu sebanyak $30,1 \%$ dan paling sedikit pada rentang umur $\geq 67$ tahun yaitu sebanyak $2,7 \%$. Berdasarkan tingkat pendidikan responden yang menderita kanker payudara terbanyak pada tingkat pendidikan Diploma/Perguruan Tinggi yaitu sebanyak $35,6 \%$, sedangkan tingkat pendidikan tertinggi responden pada kelompok kontrol yaitu SMA/sederajat sebanyak $34,2 \%$. Berdasarkan jenis pekerjaan, kelompok kasus maupun pada kelompok kontrol terbanyak adalah ibu rumah tangga yaitu sebanyak $35,6 \%$ pada kasus dan $56,2 \%$ pada kelompok kontrol. 
Tabel 1. Karateristik Responden

\begin{tabular}{|c|c|c|c|c|c|c|}
\hline \multirow{2}{*}{ Karakteristik } & \multicolumn{2}{|c|}{ Kasus } & \multicolumn{2}{|c|}{ Kontrol } & \multicolumn{2}{|c|}{ Jumlah } \\
\hline & $\mathbf{n}$ & $\%$ & $\mathbf{n}$ & $\%$ & $\mathbf{n}$ & $\%$ \\
\hline \multicolumn{7}{|l|}{ Kelompok Umur (tahun) } \\
\hline $25-31$ & 4 & 5,5 & 4 & 5,5 & 8 & 5,5 \\
\hline $32-38$ & 9 & 12,3 & 9 & 12,3 & 18 & 12,3 \\
\hline $39-45$ & 13 & 17,8 & 13 & 17,8 & 26 & 17,8 \\
\hline $46-52$ & 22 & 30,1 & 22 & 30,1 & 44 & 30,1 \\
\hline $53-59$ & 10 & 13,7 & 10 & 13,7 & 20 & 13,7 \\
\hline $60-66$ & 13 & 17,8 & 13 & 17,8 & 26 & 17,8 \\
\hline$\geq 67$ & 2 & 2,7 & 2 & 2,7 & 4 & 2,7 \\
\hline \multicolumn{7}{|l|}{ Tingkat Pendidikan } \\
\hline Tidak Sekolah & 1 & 1,4 & 2 & 2,7 & 3 & 2,1 \\
\hline Tidak tamat SD & 1 & 1,4 & 1 & 1,4 & 2 & 1,4 \\
\hline $\mathrm{SD}$ & 14 & 19,2 & 17 & 23,3 & 31 & 21,2 \\
\hline SMP/Sederajat & 12 & 16,4 & 14 & 19,2 & 26 & 17,8 \\
\hline SMA/Sederajat & 19 & 26,0 & 25 & 34,2 & 44 & 30,1 \\
\hline Diploma/PT & 26 & 35,6 & 14 & 19,2 & 40 & 27,4 \\
\hline \multicolumn{7}{|l|}{ Pekerjaan } \\
\hline Tidak Bekerja & 7 & 9,6 & 4 & 5,5 & 11 & 7,5 \\
\hline IRT & 26 & 35,6 & 41 & 56,2 & 67 & 45,9 \\
\hline Petani & 1 & 1,4 & 1 & 1,4 & 2 & 1,4 \\
\hline PNS & 17 & 23,3 & 7 & 9,6 & 24 & 16,4 \\
\hline Wiraswasta & 13 & 17,8 & 6 & 8,2 & 19 & 13,0 \\
\hline Pensiunan & 5 & 6,8 & 11 & 15,1 & 16 & 11,0 \\
\hline Dosen & 2 & 2,7 & 1 & 1,4 & 3 & 2,1 \\
\hline Karyawan Swasta & 2 & 2,7 & 2 & 2,7 & 4 & 2,7 \\
\hline
\end{tabular}

Sumber : Data Primer, 2016

Variabel konsumsi lemak, terbanyak pada responden yang menderita kanker payudara yaitu sebanyak 46,6\% sedangkan pada kontrol yaitu sebanyak 22,3\%. Variabel obesitas lebih banyak pada kelompok kasus yaitu sebanyak $57,5 \%$ dan pada kelompok kontrol yaitu sebanyak $41,1 \%$. Variabel merokok diketahui bahwa hanya 1 orang responden yang merokok $(1,4 \%)$ yaitu pada kelompok kasus. Variabel status keluarga yang merokok di rumah, lebih banyak ditemukan pada kelompok kasus yaitu sebanyak $74,0 \%$ sedangkan pada kelompok kontrol sebanyak 58,9\%. Responden yang tidak memiliki keluarga yang merokok di rumah lebih banyak ditemukan pada kelompok kontrol yaitu sebanyak $41,1 \%$ dan pada kelompok kasus 26,0\%. Variabel frekuensi merokok keluarga di rumah, pada kelompok kasus memiliki keluarga yang setiap hari merokok di rumah yaitu sebanyak $68,5 \%$ dan pada kelompok kontrol yaitu sebanyak $52,1 \%$. Variabel status merokok, terbanyak yaitu dengan status perokok pasif pada kelompok kasus sebanyak 50 orang $(68,5 \%)$ dan pada kelompok kontrol yaitu sebanyak $52,1 \%$, sedangkan yang tidak merokok dan bukan perokok aktif lebih banyak pada kelompok kontrol yaitu sebanyak 35 orang $(47,9 \%)$ dan pada kelompok kasus sebanyak 23 orang $(31,5 \%)$. Variabel stres lebih banyak dialami oleh penderita kanker payudara yaitu sebanyak 30 orang $(41,1 \%)$ dan pada kelompok kontrol yaitu sebanyak 15 orang $(20,5 \%)$.

Berdasarkan hasil uji bivariat statistik dengan menggunakan OR (Tabel 2), diketahui bahwa responden yang memiliki konsumsi lemak dengan risiko tinggi lebih banyak ditemukan pada kelompok kasus yaitu sebanyak 34 orang $(46,6 \%)$ sedangkan pada kelompok kontrol yaitu sebanyak 17 orang $(23,3 \%)$ dengan nilai $\mathrm{OR}=2,872$ (CI 95\%; 1,410-5,849) dengan $\mathrm{p}=0,005$. Secara statistik bermakna antara responden yang memiliki konsumsi lemak $\geq$ nilai rata-rata seluruh penderita/responden $(\geq 97)$ dengan kejadian kanker payudara dengan kata lain konsumsi lemak me- 
rupakan faktor risiko terhadap kejadian kanker payudara.

Obesitas dengan risiko tinggi lebih banyak ditemukan pada kelompok kasus yaitu sebanyak 42 orang $(57,5 \%)$ sedangkan pada kelompok kontrol yaitu sebanyak 30 orang $(41,1 \%)$ dengan nilai $\mathrm{OR}=1,942$ (CI 95\%:1,006-3,749) dengan $\mathrm{p}=0,069$. Secara statistik bermakna antara obesitas dengan kejadian kanker payudara. Dengan kata lain, obesitas merupakan faktor risiko kejadian kanker payudara. Merokok atau memiliki suami sus $(41,1 \%)$ dibandingkan pada kelompok kontrol $(20,5 \%)$ dengan nilai OR=2,698 (CI 95\%:1,2994$5,624)$ dengan $p=0,012$. Secara statistik bermakna antara stres dengan kejadian kanker payudara. Dengan kata lain stres merupakan faktor risiko terhadap kejadian kanker payudara (Tabel 2).

Variabel yang diduga merupakan faktor penyebab kejadian kanker payudara akan dijadikan calon uji multivariat. Variabel yang akan diikutkan adalah variabel yang mempunyai nilai $\mathrm{p}<0,25$. Ketentuan nilai $\mathrm{p}<0,25$ adalah memberi

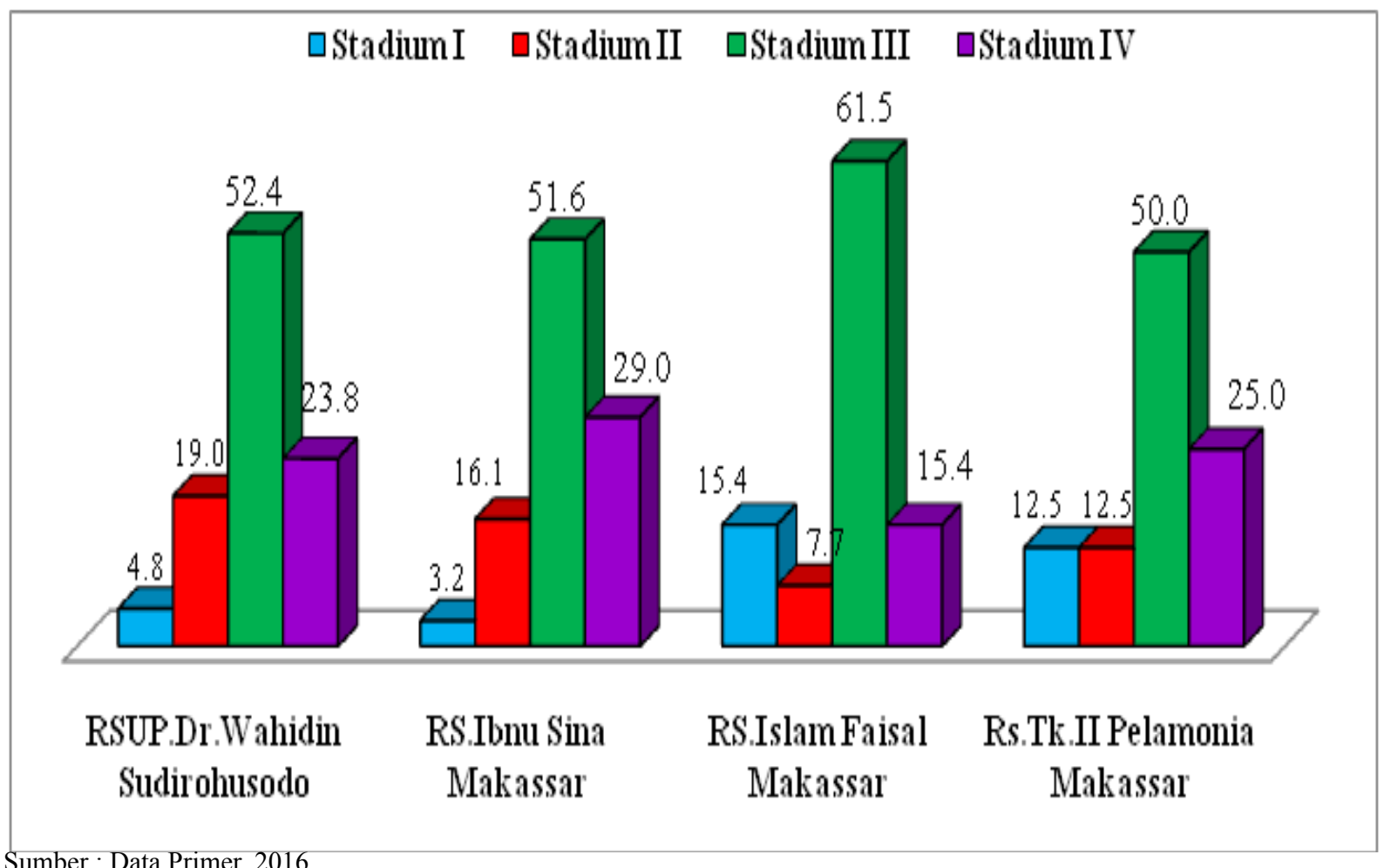

Sumber : Data Primer, 2016

\section{Grafik 1. Proporsi Responden Berdasarkan Stadium Kanker di Beberapa Rumah Sakit Kota Makassar}

atau anggota keluarga yang serumah dan menghisap rokok secara aktif lebih banyak ditemukan pada kelompok kasus $(68,5 \%)$ dibandingkan pada kelompok kontrol $(52,1 \%)$ dengan nilai $\mathrm{OR}=2,002$ (CI 95\%:1,020-3,930) dengan $\mathrm{p}=0,063$. Secara statistik bermakna antara merokok dengan kejadian kanker payudara. Dengan kata lain merokok merupakan faktor risiko terhadap kejadian kanker payudara (Tabel 2).

Responden yang memiliki total skor stres $\geq 300$ lebih banyak ditemukan pada kelompok ka- peluang variabel independen yang mungkin secara bersamaan memberikan pengaruh yang bermakna terhadap variabel dependen. Dari empat variabel yang diteliti ke-4 variabel tersebut memenuhi syarat untuk diikutkan dalam uji multivariat dengan nilai $\mathrm{p}<0,25$, yaitu konsumsi lemak, obesitas, merokok dan stres, sehingga variabel tersebut dapat dimasukkan dalam analisis multivariat dengan uji regresi berganda logistik. Diketahui bahwa dari empat variabel yang diikutkan dalam uji regresi logistik diketahui dua variabel yang 
Tabel 2. Besar Risiko Kejadian Kanker Payudara di Beberapa Rumah Sakit Kota Makassar

\begin{tabular}{|c|c|c|c|c|c|c|}
\hline \multirow{3}{*}{ Variabel } & \multicolumn{4}{|c|}{ Kejadian Kanker Payudara } & \multirow{3}{*}{$\begin{array}{c}\text { OR } \\
95 \% \text { CI(LL-UL) }\end{array}$} & \multirow{3}{*}{$\mathbf{p}$} \\
\hline & \multicolumn{2}{|c|}{ Kasus } & \multicolumn{2}{|c|}{ Kontrol } & & \\
\hline & $\mathbf{n}$ & $\%$ & $\mathbf{n}$ & $\%$ & & \\
\hline \multicolumn{7}{|l|}{ Konsumsi Lemak } \\
\hline Risiko tinggi $(\geq 97)$ & 34 & 46,6 & 17 & 23,3 & 2,872 & 0,005 \\
\hline Risiko rendah $(<97)$ & 39 & 53,4 & 56 & 76,7 & $(1,410-5,849)$ & \\
\hline \multicolumn{7}{|l|}{ Obesitas } \\
\hline Risiko tinggi (IMT $\geq 25 \mathrm{~kg} / \mathrm{m} 2$ ) & 42 & 57,5 & 30 & 41,1 & 1,942 & 0,069 \\
\hline Risiko rendah $(<25 \mathrm{~kg} / \mathrm{m} 2)$ & 31 & 42,5 & 43 & 58,9 & $(1,006-3,749)$ & \\
\hline \multicolumn{7}{|l|}{ Merokok } \\
\hline Risiko Tinggi (Perokok Pasif) & 50 & 68.5 & 38 & 52.1 & 2.002 & 0.063 \\
\hline Risiko Rendah (Tidak Merokok-Tidak Aktif) & 23 & 31.5 & 35 & 47.9 & $(1.020-3.930)$ & \\
\hline \multicolumn{7}{|l|}{ Stres } \\
\hline Risiko Tinggi $(\geq 300)$ & 30 & 41.1 & 15 & 20.5 & 2.698 & 0.012 \\
\hline Risiko Rendah $(<300)$ & 43 & 58.9 & 58 & 79.5 & $(1.294-5.624)$ & \\
\hline
\end{tabular}

Sumber : Data Primer, 2016

Tabel 3. Analisis Regresi Berganda Logistik Faktor Risiko Kejadian Kanker Payudara Pada Wanita di Beberapa Rumah Sakit Kota Makassar

\begin{tabular}{|c|c|c|c|c|c|}
\hline \multirow{2}{*}{ Variabel } & \multirow{2}{*}{ Coef } & \multirow{2}{*}{ OR } & \multicolumn{2}{|c|}{$95 \%$ CI } & \multirow{2}{*}{$\mathbf{p}$} \\
\hline & & & $\mathbf{L L}$ & UL & \\
\hline Merokok & 0.947 & 2.579 & 1.189 & 5.593 & 0.016 \\
\hline Stres & 0.977 & 2.657 & 1.166 & 6.054 & 0.020 \\
\hline Cons & $-1,293$ & & & & \\
\hline
\end{tabular}

Sumber : Data Primer, 2016

secara statistik yang bermakna yaitu merokok dengan nilai $\mathrm{p}$ value $(0,016)$, dan stres $(0,020)$ dengan nilai $\mathrm{p}<0,05$ sedangkan variabel konsumsi lemak dan obesitas dikeluarkan dari model karena mempunyai nilai $\mathrm{p}>0,05$ (Tabel 3).

\section{PEMBAHASAN}

Penyebab spesifik kanker payudara masih belum diketahui, tetapi terdapat banyak faktor yang diperkirakan mempunyai pengaruh terhadap terjadinya kanker payudara. Sehingga tujuan dari penelitian ini adalah untuk mengetahui besar risiko dari beberapa faktor yang diduga erat kaitannya dengan peningkatan kejadian kanker payudara. Beberapa faktor risiko yang dimaksud yaitu konsumsi lemak, obesitas, merokok dan stres. Perlu diingat bahwa apabila seorang perempuan memiliki faktor risiko, bukan berarti perempuan tersebut pasti akan menderita kanker payudara, tetapi faktor tersebut akan meningkatkan kemungkinan untuk menderita kanker payudara. ${ }^{20}$ Keterlambatan diagnostik dapat disebabkan oleh ketidaktahuan pasien (patient delay), ketidaktahuan dokter atau tenaga medis (doctor delay), atau keterlambatan rumah sakit (hospital delay). Sebagian besar keganasan payudara datang pada stadium lanjut. ${ }^{4}$

Konsumsi lemak merupakan salah satu faktor risiko terjadinya kanker payudara. Konsumsi lemak jenuh seperti daging, ayam goreng, fast food, susu full cream keju, mentega, telur dan gorengan akan meningkankan risiko seorang wanita untuk terkena kanker payudara. Dalam penelitian ini, frekuensi tertinggi lemak jenuh yang dikonsumsi oleh responden adalah gorengan (dengan nilai rata-rata 18,1), mentega (dengan nilai rata-rata 14,1), dan telur (dengan nilai rata-rata 13,1).

Hasil penelitian yang dilakukan oleh Balasubramaniam et al., yang menemukan bahwa wanita yang mengonsumsi lemak lebih dari $30 \mathrm{~g} / \mathrm{hari}$ memiliki risiko 2,4 kali untuk mengalami kanker payudara. ${ }^{9}$ Penelitian ini didukung pula oleh Mohite et al., yang menemukan bahwa responden yang memiliki kebiasaan mengkonsumsi lemak tambahan dalam diet memiliki risiko untuk meng- 
alami kanker payudara sebanyak 3,9 kali. ${ }^{21}$ Hal ini menunjukkan bahwa wanita yang memiliki kebiasaan dalam pola konsumsi makanan berlemak dapat menyebabkan tubuh menghasilkan lebih banyak estrogen dan akan memicu proses pembelahan sel yang tidak normal. Senyawa lemak juga menghasilkan radikal bebas sehingga dapat memicu pertumbuhan sel kanker. Lemak yang menumpuk dalam tubuh akan memengaruhi hormon yang pada akhinya membuat sel-sel tumbuh menjadi tidak normal dan menjadi kanker, sehingga penelitian ini menganjurkan kepada para wanita untuk mengurangi frekuensi konsumsi lemak yang biasanya dikonsumsi. Dengan mengurangi frekuensi konsumsi lemak dalam pola makan maka tingkat estrogen ada pada tingkat yang lebih rendah dan lebih aman dalam beberapa tahun ke depan.

Pola makan yang berlebihan akan mengakibatkan timbulnya obesitas. Obesitas berisiko tinggi terkena kanker disebabkan karena sel-sel lemak memproduksi esterogen, sel lemak ekstra lebih banyak memproduksi esterogen di dalam tubuh sehingga esterogen dapat memicu timbulnya sel kanker. ${ }^{22}$ Hasil penelitian ini didukung oleh penelitian Iqbal et al., di Bangladesh yang menemukan bahwa obesitas berisiko terkena kanker payudara sebanyak 5,24 kali. ${ }^{11}$ Hal ini sejalan pula dengan pelelitian yang dilakukan oleh Wang et al., yang menemukan bahwa obesitas merupakan faktor risiko untuk terkena kanker payudara sebesar 1,58 kali. ${ }^{23}$

Kedua hasil penelitian tersebut sejalan dengan teori Baradeo yang menyebutkan bahwa obesitas mempunyai efek perangsang pada perkembangan kanker payudara. Esterogen disimpan dalam jaringan adiposa (jaringan lemak). Beberapa kanker payudara adalah reseptor esterogen positif $(\mathrm{ER}+)$, artinya bahwa esterogen menstimulasi pertumbuhan sel-sel kanker payudara. Oleh karena itu, semakin banyak jaringan adiposa, maka semakin banyak esterogen yang mengikat ER+ sel-sel kanker. $^{24}$

Berdasarkan American Cancer Society, menyatakan bahwa wanita yang mengalami obesitas atau kelebihan berat badan setelah memasuki masa menopause memiliki risiko lebih tinggi menderita kanker payudara. ${ }^{10}$ Pola konsumsi yang tinggi kalori dan lemak disertai malasnya melaku- kan aktivitas fisik menjadi gaya hidup manusia modern sehingga obesitas merupakan ancaman di berbagai negara. Obesitas dapat menjadi faktor risiko penyakit apapun, termasuk kanker payudara. Para wanita yang menderita obesitas seharusnya menjadi lebih waspada terhadap kanker payudara, upaya penurunan berat badan dibarengi pola hidup seimbang merupakan pilihan yang tepat.

Perilaku merokok pada penelitian ini adalah kebiasaan atau perilaku responden maupun suami atau anggota keluarga yang serumah menghisap rokok secara aktif sebelum responden didiagnosa menderita penyakit. Perilaku merokok keluarga responden yang setiap hari merokok dapat memberikan efek terhadap peningkatan risiko kanker payudara karena asap rokok mengandung bahan kimia dalam konsentrasi tinggi yang dapat menyebabkan kanker payudara. Bahan kimia dalam asap tembakau dapat mencapai jaringan payudara. Asap rokok juga dapat memerikan efek yang berbeda terhadap risiko kanker payudara pada perokok dan mereka yang hanya terpapar asap rokok. ${ }^{15}$

Selain menghisap asap rokok, menghirup asap rokok juga merupakan suatu hal yang berbahaya. Dari hasil analisa data, ditemukan bahwa beberapa kendala dalam melakukan pola hidup, seperti kesulitan dalam menghindari asap rokok. Hal ini diketahui dari 50\% partisipan mengatakan bahwa keluarga tetap saja merokok meskipun sudah mengetahui bahwa anggota keluarga yang lain sedang sakit. Kurangnya kesadaran dan kebiasaan keluarga, menjadikan alasan keluarga sehingga tetap saja merokok meskipun mengetahui bahwa hal tersebut tidak baik. ${ }^{25}$

American Cancer Society menyebutkan bahwa perokok pasif dikenal dengan nama secondhand smoke atau Environmental Tobacco Smoke (ETS). Perokok pasif disebut demikian karena menghisap campuran dari dua bentuk asap yaitu asap dari pembakaran tembakau (asap yang berasal dari ujung rokok yang menyala, dari pipa, atau dari cerutu) dan asap utama (asap yang dihembuskan oleh perokok). Meskipun sering dianggap sama, tetapi sesungguhnya kedua asap ini berbeda. Asap dari pembakaran tembakau memiliki konsentrasi karsinogen lebih tinggi daripada asap utama. Selain itu, asap dari pembakaran tembakau memiliki partikel yang lebih kecil daripada asap utama sehingga mudah untuk masuk ke dalam 
sel-sel tubuh. Asap utama mengandung lebih dari 4.000 senyawa kimia, lebih dari 60 yang diketahui atau diduga dapat menyebabkan kanker. ${ }^{26}$

Penelitian ini sejalan dengan yang dilakukan oleh Hosseinzadeh et al., di Iran, yang menemukan hubungan faktor risiko merokok pasif terhadap kejadian kanker payudara $(\mathrm{OR}=2,76$; 95\%CI:1,51$5,04) .{ }^{16}$ Penelitian yang dilakukan di China oleh $\mathrm{Li}$ et al., juga menemukan bahwa wanita yang pernah terpapar asap rokok di rumah memiliki risiko lebih tinggi terkena kanker payudara dibandingkan dengan yang tidak pernah terpapar asap rokok dengan risiko 1,30 kali untuk terkena kanker payudara. $^{27}$

Asap rokok dapat meningkatkan risiko kanker payudara karena asap rokok mengandung bahan kimia dalam konsentrasi tinggi yang dapat menyebabkan kanker payudara. Bahan kimia dalam asap tembakau mencapai jaringan payudara dan ditemukan dalam ASI. Asap rokok juga dapat memiliki efek yang berbeda terhadap risiko kanker payudara pada perokok dan mereka yang hanya terpapar asap rokok.

Stres juga dapat menjadi faktor risiko terserang kanker payudara. Pengertian stres adalah suatu kondisi atau keadaan tubuh yang terganggu karena tekanan psikologis. Biasanya, stres dikaitkan bukan karena penyakit fisik, tetapi lebih mengenai kejiwaan. Lantaran pengaruh stres tersebut, penyakit fisik bisa muncul akibat lemahnya dan rendahnya daya tahan tubuh pada saat tersebut. Banyak hal yang bisa memicu stres, seperti rasa khawatir, perasaan kesal, capek, frustasi, perasaan tertekan, kesedihan, pekerjaan yang berlebihan, Pre Menstrual Syndrome (PMS), terlalu fokus pada suatu hal, perasaan bingung, berduka cita, dan rasa takut. ${ }^{28}$

Salah satu alat untuk mengukur tingkat stres seseorang adalah dengan menggunakan Skala Holmes. Berdasarkan hasil perhitungan nilai skor dari setiap pertanyaan akan dihitung nilai rata- rata responden. Bila nilai rata-rata responden $\geq 300$ maka responden mengalami stres. Dalam penelitian ini stres merupakan faktor risiko terhadap kejadian kanker payudara. Penelitian ini sejalan dengan penelitian yang dilakukan oleh Hosseinzadeh et al., yang menemukan bahwa stres merupakan faktor risiko terjadinya kanker payudara sebesar 3,05 kali. ${ }^{16} \mathrm{Hal}$ ini sejalan pula dengan penelitian oleh Kocic et al., yang menemukan bahwa stres merupakan faktor risiko kanker payudara. Dengan stres tertinggi pada kematian anggota dengan risiko sebesar 7,98 kali untuk terjadinya kanker payudara. ${ }^{29}$ Serupa dengan penetian ini, Lee \& Yeh, menemukan bahwa stres merupakan faktor risiko terjadinya kanker payudara sebanyak 1,124 kali. $^{30}$

Banyak hal yang dapat memicu terjadinya stres pada seorang wanita diantaranya seperti rasa khawatir, perasaan kesal, capek, frustasi, perasaan tertekan, kesedihan, pekerjaan yang berlebihan, Pre Menstrual Syndrome (PMS), terlalu fokus pada suatu hal, perasaan bingung, berduka cita, dan rasa takut. ${ }^{28}$ Steven E. Keller, dkk. dalam Hawari, berbagai penelitiannya telah menemukan keterkaitan antara stres psikososial, depresi, imunitas dan kesehatan fisik. Penelitiannya memperkuat peneliti-peneliti sebelumnya seperti Selye, Glaser dkk, Solomon yang antara lain menyatakan bahwa stres psikososial akan mengakibatkan stres psikobiologik yang berdampak pada menurunnya imunitas tubuh. Bila imunitas tubuh menurun maka yang bersangkutan rentan jatuh sakit baik fisik maupun mental yang dapat mengarah pada risiko munculnya sel-sel ganas (kanker) ${ }^{31}$ Kondisi stres akan memompa hormon estrogen lebih banyak. Hormon estrogen berlebih adalah faktor utama pemicu kanker payudara.

Berbeda dengan hasil penelitian yang dilakukan oleh Schoemaker et al., bahwa tidak ada hubungan risiko kanker payudara dengan frekuensi mengalami stres $(\mathrm{RR}=0,87,95 \% \mathrm{CI}: 0,78-0,97){ }^{32}$ Hal ini menunjukkan bahwa stres yang dialami agar sebisa mungkin untuk dikontrol serta menghindari hal-hal yang dapat menyebabkan stres sehingga risiko untuk terkena kanker payudara akan semakin rendah. ${ }^{28}$ Dengan demikian manajemen stres sangat diperlukan untuk mempercepat penyembuhan kanker payudara.

\section{KESIMPULAN DAN SARAN}

Faktor risiko gaya hidup (life style) yang berhubungan dengan kejadian kanker payudara yaitu konsumsi lemak, obesitas, merokok dan stres. Berdasarkan hasil uji bivariat statistik dengan menggunakan OR (Odds Ratio), diketahui bahwa besar risiko kejadian kanker payudara pada mereka yang sering mengkonsumsi lemak sebesar 2,872 kali 
dibanding dengan yang kurang mengkonsumsi lemak. Besar risiko kejadian kanker payudara pada mereka yang obesitas sebesar 1,942 kali dibanding dengan mereka yang tidak obesitas. Besar risiko kejadian kanker payudara pada mereka yang keluarganya memiliki prilaku merokok, maupun suami atau anggota keluarga yang serumah dan meghisap roko secara aktif sebesar 2,002 kali dibanding dengan yang tidak. Besar risiko kejadian kanker payudara pada mereka yang stres sebesar 2,698 kali dibanding dengan yang tidak stres. Hasil uji multivariat menunjukkan bahwa faktor risiko gaya hidup yang paling berpengarung terhadap kejadian kanker payudara adalah stres dengan nilai $\mathrm{OR}=2,657$. Probabilitas kejadian kanker payudara pada wanita yang sering mengonsumsi lemak tinggi dan mengalami stres adalah $65,3 \%$.

Disarankan bagi wanita sebaiknya lebih proaktif dalam melakukan deteksi dini dan menerapkan pola hidup sehat dengan mengonsumsi makanan yang sehat dan bergizi serta menghindari makanan yang mengandung lemak tinggi utamanya pada wanita yang memiliki riwayat obesitas. Wanita yang memiliki anggota keluarga yang merokok agar memotivasi keluarganya untuk menghentikan kebiasaan tersebut. Serta berusaha untuk mengindari stres.

\section{UCAPAN TERIMA KASIH}

Ucapan terimakasih dan penghargaan kepada Tim Pembimbing Penelitian, Fakultas Kesehatan Masyarakat program Pasca Sarjana UNHAS, Direktur RSUP Dr. Wahidin Sudirohusodo, RS TK II Pelamonia, RS Ibnu Sina dan RS Islam Faisal, para responden serta rekan-rekan mahasiswa magister jurusan Epidemiologi.

\section{DAFTAR PUSTAKA}

1. WHO. What Is Breast Cancer? 2016 [Diakses pada tanggal 23 Februari 2017]. Available from:http://www.cancer.org/cancer/breastcancer/detailedguide/breast-cancer-what-isbreast-cancer.

2. Kemenkes RI. Situasi Penyakit Kanker. Buletin Jendela Data dan Informasi Kesehatan 2015.

3. Global Burden Cancer 2012 : Estimated Cancer Incidence, Mortality and Prevalence Worldwide in 2012 [Internet]. IARC. 2012 [cited Diakses pada tanggal 17 Maret 2016]. Available from: http://globocan.iarc.fr/Pages/ fact_sheets_population.aspx.

4. Suyatno. Bedah Onkologi Diagnosis dan Terapi. Jakarta: Sagung Seto; 2010.

5. Perry CS, Otero JC, Palmer JL, Gross AS. Risk Factors for Breast Cancer in East Asian Women Relative to Women in the West. Asia-Pacific Journal of Clinical Oncology. 2009;5(4).

6. Kozier B. Fundamentals of Nursing: Concepts, Process and Practice. New Jersey: Pearson; 2004.

7. Potter, Perry. Fundamental Keperawatan Konsep, Proses dan Praktik. 4 ed. Jakarta: EGC; 2005.

8. Noormindhawati L. Tahukah Anda? Makanan Berbahaya untuk Kanker. Jakarta Timur: Dunia Sehat; 2014.

9. Balasubramaniam SM., Rotti SB., Vivekanandam. Risk Factors of Female Breast Carcinoma: A case Control Study at Puducherry. Indian Journal of Cancer. 2013;50(1).

10. American Cancer Society. Breast Cancer; What are the Risk Factors for Breast Cancer?2016 Online pada tanggal 15 Januari 2016. Available from: http://www.cancer.org/ cancer/breastcancer/detailedguide/breast-cancer-risk-factors.

11. Iqbal J, Ferdousy T, Dipi R, Salim R, WeiWu, Narod SA, et al. Risk Factors for Premenopausal Breast Cancer in Bangladesh. International Journal of Breast Cancer. 2015;2015(7).

12. Annova. Hubungan Antara Merokok dan Kanker2012 Diakses pada tanggal 23 Februari 2017. Available from: http://artikelduniawanita.com/hubungan-antara-merokok-dan-kanker.html.

13. Asian Cancer. Membuka Rahasia Mengenai "Kanker Payudara"2012 Diakses pada tanggal 23 Februari 2017.

14. Kelsey JL, Gammon MD. The Epidemiology of Breast Cancer. CA: A Cancer Journal for Clinicians. 2008;41(3).

15. Savitri A. Kupas Tuntas Kanker Payudara, Leher Rahim \& Rahim. Yogyakarta: Pustaka Baru Press; 2015.

16. Hosseinzadeh M, Ziaei JE, Mahdavi N, Aghajari P, Vahidi M, Fateh A, et al. Risk Factors for Breast Cancer in Iranian Women: A Hospi- 
tal-Based Case-Control Study in Tabriz, Iran. Journal of Breast Cancer. 2014;17(3):236-4.

17. Hawari D. Manajemen Stres, Cemas, dan Depresi. Jakarta: Balai Penerbit Fakultas Kedokteran Universitas Indonesia; 2001.

18. Kashani F, Babaee S, Bahrami M, Valiani M. The effects of Relaxation on Reducing Depression, Anxiety and Stress in Women Who Underwent Mastectomy for Breast Cancer. Iranian Journal of Nursing and Midwifery Research. 2012;17(1).

19. Lemeshow. Besar Sample Dalam Peneltian Kesehatan. Yogyakarta: Gajahmada University Press; 1997.

20. Rasjidi I. 100 Question \& Answer: Kanker Pada wanita. Jakarta: PT Elex Media Komputindo; 2010.

21. Mohite VR, Pratinidhi AK, Mohite RV. Dietary Factors and Breast cancer: A Case Control Study from Rural India. Asian Journal of Medical Sciences. 2014;6(1).

22. Breastcancer.org. Being Overweight 2017 Diakses pada tanggal 23 Februari 2017. Available from: http://www.breastcancer.org/risk/ factors/weight.

23. Wang X-L, Jia C-X, Liu L-Y, Zhang Q, Li Y-Y, Li L. Obesity, Diabetes Mellitus, and the Risk of Female Breast Cancer in Eastern China. World Journal of Surgical Oncology. 2013;11(71).

24. Mary Baradero., Mary Wilfrid Dayrit., Yakobus Siswadi. Seri Asuhan Keperawatan: Klien Gangguan Sistem Reproduksi \& Seksualitas.
Jakarta: EGC; 2006.

25. Yanti RN. Pola Hidup Pasien Kanker Payudara Selama Kemoterapi di RSUP H Adam Malik Medan [Skripsi]: Universitas Sumatera Utara; 2015.

26. American Cancer Society. Breast cancer2011 Diakses pada tanggal 4 Mei 2016. Available from: http://www.cancer.org/Cancer/BreastCancer/index.

27. Li B, Wang L, Lu M-S, Mo X-F, Lin F-Y, Ho5 SC, et al. Passive Smoking and Breast Cancer Risk among Non-Smoking Women: A Case-Control Study in China. Plos One. 2015;10(4).

28. Putra SR. Buku Lengkap kanker Payudara. Yogyakarta: Laksana; 2015.

29. Kocic B, Filipovic S, Vrbic S, Pejcic I, Rancic N, Cvetanovic A, et al. Stressful life Events and Breast Cancer Risk: A Hospital-Based Case-Control Study. JBUON. 2015;20(2):48791.

30. Lee T-Y, Yeh M-L. A Prospective Study of the Relationship between Psychological Factors and Breast Cancer. Asia-Pacific Journal of Oncology Nursing. 2016;3(2).

31. Hawari D. Kanker Payudara Dimensi Psikoreligi. Jakarta: Fakultas Kedokteran 2004.

32. Schoemaker MJ, Jones ME, Wright LB, Griffin J, McFadden E, Ashworth A, et al. Psychological Stress, Adverse Life Events and Breast Cancer Incidence: A Cohort Investigation in 106,000 Women in the United Kingdom. Breast Cancer Research. 2016;18(72). 